\title{
Heading For Cyberspace: Planning A Strategy For Success With Online Classes
}

Jane Whitney Gibson, (Email: JWGibson1@aol.com), Nova Southeastern University Charles W. Blackwell, (Charlie@ huizenga.nova.edu), Nova Southeastern University

\begin{abstract}
This paper focuses on the 3 P's of a successful strategy for delivering online classes: Platform, Protocols, and Pedagogy. First the paper examines the commonly available online platforms used by schools with web-based programs. Next, the authors suggest a fundamental list of protocols to provide consistency and quality control across classes. Finally, a list of pedagogical questions is presented to suggest strategies for setting up individual classes.
\end{abstract}

\section{INTRODUCTION}



ith the turn of the millennium, the meaning of distance education has changed from traditional classes being taught at off-campus locations during times convenient to adult learners to including a plethora of classes taught either entirely online or in an online/on ground hybrid format.

The authors are business school professors who have taught face-to-face classes on and off campus for over 20 years. In their roles as administrators, they helped Nova Southeastern University's distance programs evolve to include online degree offerings. Since the mid 1990s, each of the authors has taught dozens of online courses using a variety of platforms. They have attended conferences and written articles about success in cyberspace.

This paper focuses on the 3 P's of a successful strategy for delivering online, college-level, business classes: Platform, Protocols, and Pedagogy. First the paper examines the commonly available online platforms used by schools with web-based programs. These include WebCt, Blackboard, and Outlook Express. Next the authors suggest that a fundamental list of protocols be designed that create consistency among online courses and a measure of student comfort in this relatively new environment. Finally, a list of pedagogical questions is presented to suggest strategies for setting up individual classes. These include transisting to the role of facilitator from that of traditional instructor and advice on how to make learning materials appropriate for cyberspace.

Before anything else can be done, the program office must decide which platform to use for the online program.

\section{PLATFORMS}

When one of the authors led the efforts to take an undergraduate business program online in the mid 1990s at Nova Southeastern University, classes were offered on instructors' individual websites. These instructors were forced to learn HTML coding in order to set up their classes and the look and feel of each class differed substantially. Using this system, it took eighteen months to begin an online program, a process which has been described elsewhere. (Gibson \& Herrera, 1999)

In less than ten years, however, the standard has changed from individual or university platforms to standard course management systems such as WebCt, Outlook Express, eCollege, or Blackboard. These platforms provide 
space for course postings and interactions as well as integrated email systems and utilities for test administration and grade reports.

Says one early adopter:

This technology is responsible for attracting large numbers of instructors to engage in online delivery of courses, as platforms load course content in the form of "objects" which precludes the need for coding proficiency on the part of participating faculty members. "Object orientations" are also prominent in personal computer applications and peripherals that may be used to develop communication tools for insertion on courseware management platforms. (Tesone, 2004, 63)

According to Ullman and Rabinowitz (2004) and consistent with the authors' findings, whichever course management system is chosen, three main functions can be found: a virtual community capacity, authoring and publishing tools, and data management capabilities. The capacity to create a virtual community is key to any online experience. The commercial platforms allow online communication via discussion boards, email, chat sessions which, in some cases, are augmented by a white board and the capability to incorporate PowerPoint slides. The authoring and publishing tools allow instructors to upload their course materials to the platform for easy student access. They also facilitate the creation of online tests. The data management functions take care of the administrative chores of creating classes, enrolling students, and tracking the student's progress through grade functions.

Deciding which platform to use is an administrative responsibility which usually depends heavily on comparative costs and service. Regardless of the decision, however, a comprehensive training program needs to be available for faculty to enable them to use the software to maximum advantage. Although beyond the scope of this paper, training online faculty in all aspects of the platform, protocols, and pedagogy is an important key to the success of any online program.

\section{PROTOCOLS}

When planning an online program, it is important to establish protocols which all faculty members will follow in teaching their cyberclasses. Students in programs which lack these protocols complain about the lack of consistency from one class to another. At best, they experience the typical student-teacher getting-to-know-you phase which onground students experience. During that time, students are trying to figure out what this new faculty member expects from the students and what the students can expect in return. At worst, online students experience a total disconnect and are left feeling abandoned and bewildered. Remembering that most online courses are accelerated, even the best case scenario wastes valuable course time while students try to adjust to the new course environment. In the worst case scenario, students drop the course in droves.

Protocols are designed to remove as much of the mystery from class as possible. Both students and faculty should know what to expect. Faculty protocols provide consistency from class to class and eliminate many student complaints about one faculty member's requirements as compared to another faculty member's requirements. Individual faculty members, for example, should not be deciding how many days a week are required for student participation in a given course. The large online programs, such as Baker and the University of Phoenix, are very good in training the faculty on these protocols and ensuring that they are followed by using faculty meetings and course peer-evaluation for control. Each program has extensive instructions regarding faculty expectations on each course contract. Baker has gone a step further and established the "Baker Dozen," a cute way to call attention to their mandatory instructor protocols.

Protocols do not take away academic freedom. Instructors are free to use their own lecture notes, materials, examples, exams, etc. They do, however, provide a recognizable framework that distinguishes one program from another and trains students to expect certain things in each class. For example, a faculty and student protocol in all University of Phoenix online classes is that students will be divided into learning teams in each and every course and a significant amount of the class work will be done in those teams. Every UoP student knows that he or she is going to 
be a member of a learning team in every class. If a person doesn't like working in teams, then this program is not for him or her. Another example is that in every Nova Southeastern University online eMBA class, there will be integration of the Value Driven Management theory originated by the NSU business school dean. The VDM model at NSU and the learning team concept at UoP are distinctive competitive advantages which are ensured by faculty protocols.

Clearly articulated and reinforced protocols for both students and faculty establish the frame of the course. Within this framework, coursework is presented and students and faculty interact according to some established guidelines. Figure1 lists suggested protocols for faculty which are among the best that the authors have encountered.

Figure 1

Suggested Protocols for Faculty

\begin{tabular}{|l|l|}
\hline Time & Faculty Protocol \\
\hline Pre & Send introductory email to students directing them to class \\
\hline Pre & Post syllabus, getting started note, wk 1 lecture notes and discussion questions before the class starts \\
\hline During & Post weekly lecture notes at least 2 days before the corresponding week starts \\
\hline During & $\begin{array}{l}\text { All online weeks start on Monday and end on Sunday (or whatever other combination the program decides } \\
\text { upon) }\end{array}$ \\
\hline During & All faculty are expected to be active in the online class at least 5 days a week and never absent 2 days in a row. \\
\hline During & Post biosketch, require students to post biosketches and respond to each other \\
\hline During & Maintain 24-36 hour turnaround on all emails \\
\hline During & Require and grade 5 days of student participation each week (or however many days the program decides upon) \\
\hline During & Return all major assignments with comments and grades within one week \\
\hline During & Send individual grades at the end of each week \\
\hline After & Return term papers with comments and final course grades within one week \\
\hline
\end{tabular}

Note in Figure 1 that the suggested protocols define the online course environment for both the new and returning online instructor. Each class in a given program maintains the same protocols and by agreeing to teach a course, the individual faculty member agrees to abide by these protocols. Some are static guidelines such as the fact that the online week for all classes begins on a certain day and ends on a certain day. Most require the instructor to do something such as send an introductory message to students just prior to the first day of class. In addition to the traditional evaluation points of content knowledge and the ability to communicate effectively, online instructor evaluations are very much tied to how fully and consistently faculty members meet these protocols.

Protocols also establish clear expectations for students. Figure 2 suggests program protocols for students. The first protocol, buying books before the class starts, is one that potentially causes problems on the first day of class. Since online courses are often offered in an accelerated format, it is important that students have their books and be ready to participate on Day 1 . The University of Phoenix has recently found a way to avoid the problems associated with students getting books by going to an e-book format where all course materials are available to students in the online environment. With more than 60,000 students online, UoP is in a position to negotiate e-book arrangements with publishers, but the authors expect that this trend will trickle down to smaller schools in the next few years

Student protocols define what students are expected to do in all of their classes irrespective of the subject or course instructor. Protocols such as the one on demeanor define program expectations of all students and help to set the tone of the online classroom. Participation protocols let perspective and active students know that the online course environment is a rigorous one and should not be confused with less-rigorous correspondence courses where students are free to work on their own and have no responsibility to share their learning experience with classmates. cyberspace.

Faculty and student protocols in turn lead to pedagogical issues for the faculty member heading for 
Figure 2

Suggested Protocols for Students

\begin{tabular}{|l|l|}
\hline Time & Student Protocol \\
\hline Pre & Buy books and other required materials \\
\hline During & Check into class on Day 1, print and read syllabus \\
\hline During & Post lengthy biosketch in first 2 days, welcome others \\
\hline During & Complete all weekly assignments on time \\
\hline During & $\begin{array}{l}\text { Meet participation requirements by making a significant participation in the course the required number } \\
\text { of days }\end{array}$ \\
\hline During & Maintain professional demeanor in all conversations; respect the opinions of others \\
\hline During & Ask general questions on the bulletin board; ask personal questions in an email to instructor \\
\hline During & Practice graduate level writing skills on all assignments and use APA style on all research assignments. \\
\hline
\end{tabular}

\section{PEDAGOGY}

Transisting to the online environment requires that faculty rethink how they teach their classes. In place of the overhead projector and VCR for playing videos, for example, the online professor may use PowerPoint slides and links to video and print material on a given subject. The authors recommend, however, that online faculty embrace a "least technical common denominator" and for the moment, avoid video links, streaming video, and other technology that not every student may currently have. By planning for the student who is working on a modest personal computer with dial-up connection, you are ensuring that nobody will be left out.

It is important to keep in mind that the philosophy of online teaching is different than the traditional classroom where the old "sage on the stage" model might still be effective. Online professors, especially those working with adult students, are cast as facilitators of learning rather than purveyors of knowledge. In making this transition, several questions need to be answered.

\section{Should my class be asynchronous or synchronous or a combination of both?}

Provided this decision has not already been made for you by the program office, you need to consider how you want students to access class. Do you want predominantly asynchronous connections where students can log on and work at any time, or do you prefer synchronous chats where students are required to be in class at specific times. Note that if you do require chats, you need to learn how to manage them. Unmanaged chats, especially with large numbers of students, can be frustrating and non-productive for everyone. You can also choose to have brief chats scattered through the class that students can attend on a voluntary or mandatory basis. Remember that the main reason students take online classes is to avoid specific time and location constraints. The average online class has students from different time zones and attending chats is often not convenient. The authors prefer online classes which are $100 \%$ asynchronous but they have faculty colleagues who use chats quite effectively.

\section{What should I put in the syllabus?}

The syllabus is the guiding document of the course. Think of it as a contract. Avoid the traditional 2-3 page syllabus and construct a much longer document. Online classes typically have multiple student requirements for each week. The authors' classes typically require answers to discussion questions, some type of case assignment, a weekly summary paper, and a specified number of days of participation. A weekly summary of assignments and due dates if very helpful for students and should be easily found in the syllabus. Fully describe your expectations for all assignments; carefully explain what is due and where. Discuss your research expectations and stress the importance of avoiding plagiarism. Explain what plagiarism is and what will happen if you encounter any. Some programs like the University of Phoenix have large sections of boiler-plate material for each syllabus; others allow the faculty member complete freedom as long as they follow a certain format. The authors recommend that the online faculty member should constantly refine their syllabus as questions arise. The goal is that the great majority of questions students might have should be answered in the syllabus. 


\section{How should I present my "lectures?"}

Lecture material can be typed in Word files and uploaded to whatever platform you are using. This is the material that you would be giving students in traditional classes during class time. In online classes, you can easily supplement your typed notes by posting external links to related material. The authors represent "chunking" the work into weekly modules and posting Weekly Lecture Notes about two days before the start of each new online week. In the many programs of which the authors have knowledge, the standard is that weekly lecture notes are followed by weekly discussion questions which form some or all of the weekly student assignment. Student answers to these discussion questions are due on the same day every week and serve to spur conversation on the week's lecture topics.

\section{How do I organize my class?}

It is easy for students to get lost in an online class. The responsibility is on the instructor to organize the course so that students know exactly what to do and when to do it. The authors recommend modularizing the work so that there is a discrete amount of work to be done in each online week. Typically, in addition to the discussion questions mentioned above, we use at least two other small assignments each week. Open threads for students to post their answers for each assignment and in which they can discuss and critique each other's assignments. In addition, we use some type of integrating, course-long assignment like a term paper which is typically submitted through the platform's student dropbox or to the instructor's email by attachment. While weekly assignments and graded participation account for at least $50 \%$ of the course grade, major assignments and/or midterm and final exams still account for a large portion of the student's final grade.

\section{How do I get students to participate?}

This is a problem many new online faculty members experience. Student interaction is critical to the success of the course. Says one expert,

The need for interaction is imperative. Courses with little interaction have high drop-out rates. E-mail, chat rooms, and discussion boards remove the feeling of isolation and provide opportunities for discussion. (Charp, 2002, Para. 13)

The easiest way to get students to participate is to require it and grade it. When faculty members send out weekly grades to each student (see faculty protocols), participation should be among the grade points. Be sure that students know exactly how many days they must participate and what your definition of participation is; otherwise, you will get arguments that someone's "I agree" message constitutes a day's participation.

\section{How do I establish a collaborative learning environment?}

The authors experience has consistently been that they get to know their online students far better than their traditional students. Constant interaction is the key. Model the behavior that you want from students by being consistently available to the class. Be friendly and collegial and encourage interaction. Throw out open-ended questions regarding weekly topics and keep the resulting conversation going. It is important for the instructor not to be the focal point of the class conversation. You have given them the lecture notes and asked probing questions. If you are dealing with adult students, they are perfectly capable of bringing their experiences to bear on almost any question you can ask. Let them consult to each other and only intervene when the conversation is lagging, they are missing a piece of key information, or they are truly going in the wrong direction. You also want to intervene at the first sign of rudeness or intimidation in the classroom. In sum, the authors agree with Charp's contention that "instructors who know how to interact online with students, and are willing to give the time and effort involved, are successful." (2002, para. 14)

\section{How do I test for learning outcomes?}

One of the challenges of teaching online is testing for learning outcomes. There are many strategies for online testing but, unless students come to some central location for supervised testing, you are dealing with 
uncontrolled testing environments where traditional tests may not work. The good news is that the typical online class uses more grading points than just traditional testing so exams do not count for the majority of the student's grade. Weekly participation, modular assignments, and the integrative assignment all provide multiple grade points for the class. Still, there is room for testing in the online environment. The authors avoid objective tests although these are quite possible given the class management systems now being used. We do have colleagues who rely on timed, objective tests to assess whether students are meeting learning outcomes. We prefer a variety of applications-oriented test methodologies not excluding routine essay questions which require students to integrate and apply course material in a comprehensive way. One of the authors uses a rather unusual test modality of giving her students "mock exams" which have already been completed by a mock student. The real student first indicates whether the mock student's answers are each correct or incorrect and then writes a paragraph explaining why.

\section{CONCLUSION}

The authors believe that the proliferation of online courses will continue and accelerate as technology makes education more available to the average person. This proliferation will continue not just at the college level but at the high school level where programs such as the Florida Virtual School enrolls students in regular and honors classes. (Charp, 2002, para. 2) It will continue to develop in corporate training programs as well where "people who work with computers every day find online learning to be more attractive." (Barnes \& Blackwell, 2004, 9) Regardless of the setting, all instructors considering the trip to cyberspace must become familiar with the platforms, protocols, and pedagogical techniques most appropriate for online success.

\section{REFERENCES}

1. Barnes, B. \& Blackwell, C. (January 2004). Taking business training online: Lessons from academe. The Journal of Applied Management and Entrepreneurship, 9:1, 3-20.

2. Charp, S. (March 2002). Online learning. T.H.E. Journal Online, retrieved on 1/29/05 from http://www.thejournal.com/magazine/vault/articleprintversion.cfm?aid=3893.

3. Gibson, J. \& Herrera, J. (January 1999). How to go from classroom based to online delivery in eighteen months or less: A case study in online program development. Technological Horizons in Education Journal, 26:6, 57-61.

4. Tesone, D. (April, 2004). Fourth generation online learning for business and hospitality management schools: So far, so fast. The Journal of Applied Management and Entrepreneurship, 9:2, 57-66.

5. Ullman, C. \& Rabinowitz, M. (October 2004). T.H.E. Journal Online, Charp, S. (March 2002). Online learning. T.H.E. Journal Online, retrieved on 1/29/05 from http://www.thejournal.com/magazine/vault /articleprintversion.cfm?aid=5070. 